\title{
Speaking up about oracy: the contribution of drama pedagogy to enhanced oral communication
}

\author{
Madonna Stinson
}

\author{
School of Education and Professional Studies, Griffith University, \\ Mount Gravatt, Australia
}

Received 4 July 2015 Revised 23 August 2015 Accepted 24 August 2015

\begin{abstract}
Purpose - The purpose of this paper is to consider the growing interest in oracy and to propose the pedagogy of process drama as an ideal model for the dialogic classroom.

Design/methodology/approach - This paper takes the form of an explanatory case study where the author draws on a successful drama/oracy project in a primary school in Brisbane, Australia, to illustrate the connections between Alexander's five indicators of a dialogic classroom and the process drama in which the students participated.

Findings - The application of this process drama as pedagogy for the teaching and learning of oracy has contributed positively to students' oral communication skills and intercultural awareness. In addition, parents provide positive feedback about student engagement in school and developing self-confidence because "they have something to say".

Research limitations/implications - There was no formal pre-post test for the oral communication skills on this study, instead the researchers developed a draft "oracy" checklist which deserves further interrogation and development.

Practical implications - There are implications for the use of process drama as a means of creating and sustaining the dialogic classroom. Teacher professional development would be required to assist the planning and delivery of dramas that allow for the deep and complex learning evidenced in this study.

Social implications - This is an ideal vehicle for assisting in the development of empathy, collaboration, emotional intelligence and intercultural understanding.

Originality/value - This is an example of an extremely high-quality curriculum plan and implementation. The importance of engaging in implicit and explicit instruction of oral communication for the twenty-first century should not be underestimated. The process drama allows oral language to be foregrounded, with additional learning opportunities from a range of other learning areas, brought together in a coherent and complex model of practice.
\end{abstract}

Keywords Pedagogy, English language arts, English teaching, Dialogic classroom, Oracy, Speaking and listening, Process drama, Oral language pedagogy

Paper type Research paper

\section{Introduction}

Developing the oral language and vocabulary skills of children, particularly those who are learning English as a second language or those who spent their pre-school years in language restricted environments is one of the greatest challenges facing educators (Pikulski and Chard, 2005, p. 514). 
ETPC 14,3

It is probably a truism to point out that we are living in a world where the focus on learning language and language competency is constantly changing. Neither is there a need to emphasise the increased prominence of the learning of the grammatical and structural aspects of English language; the "back to basics" movements worldwide will do that for us. What is intriguing, however, is an emerging focus on the development of oral communication, something that may have been sidelined or de-emphasised with the increased focus on reading and writing. Interestingly, a Monash University Employer Survey (2007) placed oral communication skills as number one of their foundation skills, as did the University of South Australia Employer Survey (2008).

Despite this valuing of oral language and communication skills in the post-schooling arena, the common perception seems to be that talk is a natural act, and little attention is given to it as part of the formal school curriculum. Honig (2007, p. 582) claims that, "many people believe you don't have to teach" oral language because most children appear to have extensive vocabularies when they enter kindergarten. Jones (2007, p. 569) adds:

It may be assumed that because talk is interwoven into the fabric of the classroom and daily

life in general, competency develops 'naturally' and without the need for explicit teaching".

In this paper, I will discuss a particular project that used drama as pedagogy to implicitly, rather than explicitly, teach oracy. By implicitly, I mean that the learning experiences, which had the development of oracy as their primary aim, were woven into a series of process drama workshops. I propose the drama classroom to be a dialogic classroom (Alexander, 2005; Boyd and Markarian, 2011; Lyle, 2008) and use evidence from the drama workshops to exemplify this. In acknowledgment of the importance of parents in learning partnerships, an interview with parents, undertaken part way through the workshop series, provided insight into their own and their children's responses to the work. Parent responses suggest that this approach add value to the overall educational experience, by providing "something to say" (Barnes, 1988, p. 46), and that the children were intensely engaged during the period of the workshop series.

\section{An emphasis on oracy}

More than 20 years ago, John O'Toole published a paper decrying the loss of a focus on oral language in discussions about literacy in schooling. In "Oracy: The forgotten basic" (O’Toole, 1991) argued for a more central positioning of oracy within the classroom, both in terms of literacy development, and in its own right:

Through talk we name and distance our experience, allowing us to reflect on it and transform it for use. Through talk we give others access to it, and gain access to theirs. Through talk we negotiate meaning. Through talk we gain power over our lives (O'Toole, 1991, p. 24).

Promoting the value of teaching talk for its own sake is a position supported by Hewitt and Inghilleri (1993, p. 308) who note the emphasis on the instrumental role of talk being given prominence, while the intrinsic value of teaching talking skills receive little attention. The instrumental focus is supported by "a large body of research which suggests that classroom talk is a powerful means of improving children's success in all areas of the curriculum including writing" (Bignell, 2012, p. 48 [emphasis added]). Hewitt and Inghilleri go on to explain that there have been two traditions of teaching speaking in the classroom, i.e. the Augustan tradition with the emphasis on the aesthetics of oral performance, such as recitation and performances of dramatic or poetic text and on the 
discursive tradition, talking on topic; and the romantic tradition "hearing the voice of the child" with an emphasis on expressive communication. This latter includes popular narrative and oral communication as activity taking place within face-to-face situations (Hewitt and Inghilleri, 1993, pp. 309-310).

\section{Dialogic classrooms}

Oracy has gained greater prominence in schools and in academic publications since

Robin Alexander's (Alexander, 2000, 2005, 2008, 2009; Alexander and Flutter 2009) considerable research on dialogic teaching. Alexander (2005, p. 99) notes that, in English and American classrooms, talk is initiated and dominated by the teacher in contrast to a tradition of "oral pedagogy" evident in French, Indian and Russian classrooms. It is clear which approach he prefers. Alexander promotes a dialogic classroom involving talk that is:

- collective (involving teachers and children in partnership);

- reciprocal (talking and listening and sharing ideas and viewpoints);

- supportive (without fear of "wrong" answers);

- cumulative (building on each others' ideas); and

- purposeful (with educational goals in view).

When a talk includes and represents students' views, and the discussion includes their and their teacher's ideas (i.e. the more it emerges from the romantic tradition) the more dialogic it is (Mercer et al., 2009). Monologic talk involves "reciting by heart", while dialogic talk aligns with the process of "retelling in one's own words" (Holquist, 1981, p. 341). While both have a place in any classroom, it seems clear that the second agenda needs to be urgently rearticulated to avoid a reductionist model of oracy (Haworth, 2001, pp. 21-22). Talk that is solely information-related and transactional in function limits both quality and possibilities for meaning-making and communication. An analysis of children's classroom work (Littleton et al., 2005, p. 169) has identified three different types of talk in the classroom:

(1) Disputational: Relating to unproductive disagreement.

(2) Cumulative: Where children are involved in adding uncritically to what has been said.

(3) Exploratory: Which is evident when children are actively engaged with one another's ideas.

It is evident that effective learning is more likely to take place when planning focuses on exploratory talk (Evans and Jones, 2007).

Jones (2007) claims that planning and assessment of learning should include the development of the following aspects of speaking and listening:

- Social: Developing relationships.

- Communicative: Transferring meaning.

- Cultural: Different meanings may be adopted by different speech communities (among children this might be associated with popular culture).

- Cognitive: Using talk as a means of learning. 
ETPC 14,3

It may be unsurprising that drama research claims a place in developing oracy, as language is one of the most obvious elements of drama. Wagner (1998) reported that drama experiences impact positively on language learning. Results from the large number of studies that Wagner analysed strongly indicated that learning in drama improved spontaneity, fluency, articulation, vocabulary and the use of diverse language registers. Podlozny (2000) undertook a meta-analysis of eighty studies into drama and language learning, concluding that there is substantial evidence to support claims that drama has a positive impact on a range of outcomes, particularly those relating to oral language. She went on to say that those studies using "unstructured enactment" (p. 259) rather than reproduction of script, had greater positive effect. Neelands (1992) promoted the importance of play, and other active and dramatic learning approaches, seeking to move beyond views of language learning that focus overwhelmingly on the acquisition of skills and linguistic conventions. Neelands (1992, p. 8) suggested that language learning opportunities are enhanced by:

- dialogue with an empathetic adult;

- opportunities for imaginative play; and

- an enabling environment that provides a variety of language experiences.

\section{Developing oracy through drama}

The study on which this article is based (O'Toole and Stinson, 2013a, 2013b) took place in an urban, government school close to the centre of Brisbane, Australia. Miller State School (a pseudonym), at nearly 100 years old, is a well-established and respected local school, situated in a reasonably well-off, middle-class area, although students come from a range of home circumstances. The project was undertaken at the invitation of the school leadership and aimed to use a series of drama workshops to improve oracy skills with students in a selected Year 4 class. The form of drama used is called process drama.

The term process drama (Haseman, 1991; O'Neill, 1995; O'Toole, 1991) has become widely used since the mid-1990s. However, it is sometimes misapplied to any participatory drama work. Process drama goes beyond short-term, teacher-dominated exercises by building the drama over time and incorporating the ideas, responses and negotiations of participants. All participants, including the teacher, work in and out of role as the drama progresses. Thus, it is a perfect vehicle for developing understanding of others' perspectives, as participants are "walking in the shoes of others" by accepting and participating in role within the dramatic fiction. Process dramas involve all the students all of the time, rather than being an experience where some students perform to, or for, others. Essentially, process dramas are collaboratively co-created texts, with teacher and students working in partnership to make meaning of a particular issue or idea within a dramatic context and within a particular time-frame. The experience is unrepeatable, as meaning-making and learning is a result of collaborative construction and negotiation through the medium of role. The students learn within and through the 
drama as the activities progress. The Treasure of Trivandrum drama[1] was an extended process drama that was taught over a period of three weeks.

\section{The project in action}

The drama hinged on a pretext, a hook, found in a newspaper article in The Australian (11 July, 2011), which told of the discovery of a huge treasure trove in the Padmanabaswamy temple in Kerala. The treasure, in Chamber A, was estimated to be worth around $\$ 18$ billion, and there was another, unopened chamber beyond. The newspaper article went on to talk of curses, secret passages and mysteries. What a great drama starter!

My colleague, John O'Toole and I, co-planned and co-taught the workshops, with the assistance of the regular classroom teacher. There were 22 students in this Year 4 (9-10 years) mixed gender cohort. The students had little or no prior experience of drama despite the teacher's interest in the area. Eight sequential lessons (each lasting 1-11/2 hours) were implemented over three weeks. Each session was video- and audio-recorded; students, the classroom teacher and parents were interviewed; and we audio-recorded an in-depth reflective discussion after each lesson.

We attempted to design learning activities with multiple positions of authority that shifted between student-student, student-teacher and role-role. Further, all activities were designed to facilitate negotiation, dialogue and a socially engaged approach to learning and the meaning-making process. In fact, the activities relied on the above.

Drawing on Barnes (1988, p. 46), who stated:

We talk because we have something to say. Or, to put it differently, in our everyday lives what we say, like what we write, comes out of our commitment to people, to activities and purposes, to the ongoing projects and relationships that constitute the texture of our lives. Even chat is a celebration of shared experiences and concerns.

We attempted to build a dramatic context that allowed the students to chat, to share concerns and experiences, to develop commitment to each other and to the fictional characters who played a part in the drama process.

We identified four dimensions of oracy to underpin our planning and analysis: functional, dialogical, linguistic and paralinguistic (Table I). A conventional school lesson is overwhelmingly biased towards the language of informing and controlling, initiated and sustained by the teacher, with limited or no negotiating, feeling and imagining. The process drama workshops were planned to contain opportunities for the students to practise both initiating and responding in all five dimensions. Each lesson included opportunities for the students to work individually, in pairs, in small groups, as a whole group, in and out of role.

\begin{tabular}{ll}
\hline Dimension & Functions/skills \\
\hline Functional & Informing, controlling, negotiating, feeling, imagining \\
Dialogical & Listening, responding, turn-taking, leading, narrating \\
Linguistic & Diction, vocabulary, grammar \& syntax, register, colour, public address \\
Paralinguistic & Vocal expression, non-verbal and gestural, proxemics, energy, silence and stillness
\end{tabular}

Source: Adapted from O’Toole and Stinson (2013a, 2013b, pp. 162-165)

Table I.

The four dimensions of oracy 
ETPC 14,3

Rather than maintaining an emphasis on talk, that is, information-related and transactional in function, we sought to establish learning experiences which allowed for authentic exchanges, where students were talking and listening purposefully and were able to recognize their own contributions to the learning process. The imaginative play space of the drama provided a reason and a purpose for talk and interactions. The playful and imaginative context of learning encouraged the children to take risks and experiment with language rather than being overly concerned with right or wrong answers.

\section{Drama - a dialogic pedagogy}

In the section that follows, I will provide examples of learning experiences from within the process drama that support each of the features of Alexander's dialogic classroom.

Feature 1: a dialogic classroom is collective, involving teachers and children in partnership. For each of the drama workshops, collective understanding and action were essential. The children agreed to participate in the drama work and knew the difference between the pretence and the real world. Within each workshop, they worked collaboratively in small groups or as a whole group to construct meaning and contribute to the drama. As an example, one of the very first activities was, suitably, a treasure hunt. Part sentences were hidden around the workshop space for the children to find, but when they were found they made little sense, e.g. "bars to prise open the door"; "gold coins lay about"; and "The value of the whole find has [...]". The whole class then collaborated to work out the correct sequence, which read:

A team of experts prepared to prise open the granite door of Chamber A. It took an hour for three men, straining on iron bars to prise open the door. They emerged shocked and speechless. All over the floor gold coins lay about. There were heavy belts of gold, precious stones, and other ornaments. There was one sack full of diamonds and jewellery and studded with more diamonds. A statue of temple god Vishnu was $30 \mathrm{~cm}$ high and jewel-encrusted. The value of the whole find has been estimated at $\$ 18$ billion. The statue of Lord Vishnu is itself estimated to be worth $\$ 105$ million. Armed guards have been placed around the temple to prevent looting. The traditional guardian of the temple treasure is the Maharajah, 91. He is "worried about consequences now the world knows of the treasure".

Later they were given a photocopy of the original article from the newspaper, from which these sentences had been adapted, to keep in the classroom as a resource during the period of the drama workshops. Other collaborative activities included: creating freeze frame images of the opening of Chamber A; working in small groups in roles as politicians, temple priests, developers or members of the community to discuss what they might do with a share of the wealth; collaborating to prepare "really good" vox pop questions to ask when in role as reporters; and constructing respectful rituals to present to Sri Tirunal, the Maharajah, to prove to him that they could treat the opening of the Chamber with respect.

Feature 2: a dialogic classroom is reciprocal, involving talking and listening and sharing ideas and viewpoints. Boyd and Markarian (2011, p. 519) point out that, "a key component is that the teacher is a sincere listener". I would suggest that sincere listening is key to quality interactions between all participants in dialogue. Opportunities for authentic dialogue and quality interactions where all the students participated were paramount. When they were engaging in role as reporters, the students interviewed the Maharajah, Sri Tirunal, and each other, in additional roles drawn from a range of 
members in the community of Trivandrum. Prior to any formal interviews, the students, working out of role and as themselves, were able to discuss and rehearse key ideas, contribute vocabulary and phrases, and trial interactions. This helped them ensure that the interviews they would participate in while acting as reporters, or as members of the community in the town, were as high quality as they could manage.

The "reporters" needed to listen carefully to responses so they could report back to "Charru", the chief editor (teacher-in-role), and were required to listen attentively in order to reconcile diverse viewpoints when they interviewed a child worker and her mother (both teachers in role), who had different perspectives about the child working in a sweet-making factory:

Talk is essentially a social act that occurs in a range of contexts which require children to make choices about the language that they use according to the purpose of their talk and who they are talking to (Jones and Hodson, 2012, p. 6).

The co-construction of short roleplays, rituals and planning the next steps in the drama required talking and listening and sharing ideas by all group members. A vital step in each lesson was the final, whole-class reflection time, which allowed the students and the workshop leaders to talk openly about what had gone well, or not so well, that day; what we had learnt, or found challenging; and where to from here. As the series of lessons progressed, it was notable that the students took this time more and more seriously, listening carefully to individual responses and adding in their own ideas.

Feature 3: a dialogic classroom is supportive, without fear of "wrong" answers. The process drama allowed for ideas and thoughts, rather than answers, to be shared. The nature of drama is that any sharing with each other, for example, the rituals, requires time for rehearsal and refinement before putting on a display, even if it is within the class group rather than to an external audience. The practices embedded in process drama allow for experimentation and trial, rewinding or reworking key moments and seeking out multiple ways of sharing ideas, rather than one "right" way. During the drama, the children were exposed to characters that held varying viewpoints, often at odds with each other, especially when they interviewed people from the local community about what to do with the wealth from the treasure. As such, they felt more comfortable to share thoughts that were different to those already expressed. I have mentioned above the emphasis on respect for cultural practices, artefacts, and for the high status of the Maharajah. This respectful attitude carried through to interactions with the mother and child-labourer, and seemed also to transfer to interactions between classmates.

Feature 4: a dialogic classroom is cumulative, building on each other's ideas. Even though the structure of the drama was carefully planned in advance, it was an "open" work (Eco, 1989), unfinished until the students and teachers collaborated to fill the plan with embodied interaction. The plan included increasingly complex tasks, for example, the treasure hunt and simple freeze frames in the first lesson provided the foundations for the creation of more elaborate rituals; for the spontaneous in-role interactions of the later lessons, which required the students to respond in the moment with ideas, discussion; and for actions appropriate to the specific context at that time. The collaborative devising of rituals, questions and reorganising the space to signal different locations were cumulative in nature. The teachers as facilitators of the workshops ensured that they wove in the comments and suggestions that came from the students in previous sessions. Thus, the students could see and hear that their contributions were 
ETPC 14,3

taken seriously and that they added value and interest to the ongoing work in development.

Feature 5: a dialogic classroom is purposeful, holding educational goals in view. It had been made clear to the students from the beginning of this process that there were two main aims for the project. The first was to improve speaking and listening, and the second was to learn more about another culture, in this case, India. Oral language learning was at the forefront. Involving students in the drama facilitated insights into the relationship between context, register, vocabulary and language. Many enjoyed struggling to correctly pronounce names of people and locations, and made conscious shifts of vocabulary and register when interacting with roles of different status. The reflection time at the end of each lesson heightened awareness about oral language by talking about talk, and enabled the children explicitly to identify learning and to link the learning to their own life experiences and the world outside the classroom.

\section{Parent feedback}

A small group of four parents participated in a 11/2-hour focus group interview midway through the project, where they were asked to talk about their child's response to the classes. There was unanimous agreement that their children thoroughly enjoyed the drama/oracy workshops, and that the classes were having an impact on other aspects of family life.

This group of parents marvelled at how easily and how much their participating child initiated discussion at home about the work they were doing in class. Each child "talked about these classes every night" though, in the past, schoolwork was "normally forgotten". Rather than the familiar response of "nothing" to the question "What did you do at school today?" The children had plenty to say. One of the most exciting aspects of the work for the children was that the story was based in reality: "she loved the fantasy plus the real". In the drama plan, the children had been provided with a long list of Hindu female and male names for them to choose from, and to use while in role as reporters. They were told that each of the names had a special meaning and that they could look it up on the Internet if they chose. Together with the innate tension and excitement of the true story unfolding in India, this led the children to take their parents in the evening following a workshop "to the Internet" to show and to tell them about key aspects of the story and their roles in it. One parent talked about her daughter "immersing herself" in this learning program. Another spoke of her son, who generally did not enjoy school and who struggled to make friends, feeling "happy at school and [saying] that the others in the class were listening to him and respecting his ideas".

Respect was a key aspect of the drama work. The children understood that it would be easy to fall into the use of cliché and stereotypes when working in role and could often be heard reminding each other to "work with respect" or checking "was that respectful?" This was particularly apparent when they were preparing their ideas to share with Sri Tirunal, the Maharajah (a teacher in role). In their developing intercultural awareness, they were very clear that the Maharajah was someone who both deserved and expected respectful behavior. Perhaps this transferred to their interactions with each other as well.

Another parent talked, in detail, about her daughter (let's call her Jessica), who was a non-identical twin. Jessica's brother, confident and articulate, overshadowed his sister to such an extent that their parents insisted they be in two separate classes at school, so 
that he could not take centre-stage there too. Despite this, Jessica was almost painfully shy, found it difficult to converse with anyone and never initiated conversation. Her mother reported, "For the first time in her life, she led the dinner table conversation" and, laughing, went on to report that Jessica even had the confidence to tell her brother to stop interrupting her, so she could explain what the classes were about. In a small group interview at the end of the project, Jessica, herself, explained:

I liked $[\ldots]$ the role $[. .$.$] when we were interviewing people. Like[ ... ] when I am myself, I am not$ very confident [...] but when I was in role it was easier.

One parent had been excited at the opportunity for her daughter to participate in drama to promote oracy, concerned about "a generation reliant on technology" and worried that this generation would suffer from diminished capacity to communicate owing to fewer face-to-face interactions. She had experience of both leading and participating in drama workshops and believed, along with Vygotsky (1978), who claimed speech as a cognitive act, that the workshops could help the children "organize [their] thoughts before speaking or writing".

In contrast, the other parents had not been so sure that the workshops would be of such value. They were worried that their shy or less social children would not gain much or that the drama would take time out of more important learning. In spite of these early concerns, by the mid-point of the workshop series, they were unanimously enthusiastic, pointing out how much the children were enjoying learning and school, and believing that the project had directly contributed to the changes they saw in their own children: "He felt confident in answering because there wasn't a right or wrong answer", "I think this is something where you can get the best out of every student".

\section{Conclusion}

The explicit teaching of oral communication must be given more prominence in schooling and not left to chance. Our educational community, parents and the children themselves, "need to know that effective speakers and listeners can become powerful learners, teachers and citizens" (Townsend et al., 2015, p. 576). The capacity to communicate fluently and expressively in oral exchanges across a range of complex and varied social and cultural contexts is a currency that has been long undervalued.

I would argue that a well-planned and well-executed process drama offers an ideal dialogic space for learning. In the drama described above, the children learned a great deal about their own capacities in oral communication. They had opportunities to increase their vocabulary and their known range of grammatical structures. They engaged in planned and rehearsed spoken interactions, as well as spontaneous exchanges that required them to react in the moment as they sought to solve problems and create appropriate and responsive oral texts. They made conscious decisions about paralinguistic features and vocal modulation, recognising that status and power can be shown by one's physical location in space, and that changes in pitch, pace and volume might help to enhance meaning.

All this happened while, at the same time, they were enhancing their intercultural awareness as they learned about a culture distant to their own. Through "stepping into the shoes of others", they investigated a series of complexities as they uncovered a range of views about how the riches of the treasure should be spent. Their participation in an interview with the "child", who was the same age as themselves, but who was working 

lived experiences and realise that not everyone lived with the same lifestyle or expectations. Learning in ways and through processes like this, surely helps our young people find ways to become more fully participative citizens in a global world.

The highly mobile global context of the twenty-first century makes the currency of oracy both more important and more challenging. If we want our young people to become agentic and participative citizens in today's and tomorrow's world, then it is time we turned our gaze to oracy and the enabling pedagogy of drama, within a dialogic space.

\section{Note}

1. Full details of lesson plans for a shorter version of the process drama, plus additional material, can be downloaded freely from http://artspop.org.au/content/view/?docid=28-. VYNxjlWqqko

\section{References}

Alexander, R. (2000), Culture and Pedagogy, Blackwell, Oxford.

Alexander, R. (2008), Essays on Pedagogy, Routledge, London, New York, NY.

Alexander, R.J. (2005), Towards Dialogic Teaching: Rethinking Classroom Talk, 2nd ed., Dialogos.

Alexander, R.J. (2009), Towards A New Primary Curriculum: A Report From the Cambridge Primary Review: Part 2. The Future, University of Cambridge Faculty of Education, Cambridge.

Alexander, R.J. and Flutter, J. (2009), Towards a New Primary Curriculum: a Report from the Cambridge Primary Review: Part 1 Past and Present, University of Cambridge Faculty of Education, Cambridge.

Barnes, D. (1988), “The politics of oracy”, in MacLure, M., Phillips, T. and Wilkinson, A. (Eds), Oracy Matters: The Development of Talking and Listening in Education, Cambridge University Press, Cambridge, pp. 45-54.

Bignell, C. (2012), "Talk in the primary curriculum: seeking pupil empowerment in current curriculum approaches", Literacy, Vol. 46 No. 1, p. 48.

Boyd, M.P. and Markarian, W.C. (2011), "Dialogic teaching: talk in service of a dialogic stance", Language and Education, Vol. 25 No. 6, pp. 1-20.

Eco, U. (1989), The Open Work, Cancogni, A. (Trans), Harvard University Press, Cambridge, MA.

Evans, R. and Jones, D. (2007), "Perspectives on oracy - towards a theory of practice", Early Childhood Development and Care, Vol. 177 Nos 6/7, pp. 557-567.

Haseman, B. (1991), "Improvisation, process drama and dramatic art", London Drama, July, pp. 19-21.

Haworth, A. (2001), “The re-positioning of oracy: a millennium project?", Cambridge Journal of Education, Vol. 31 No. 1, pp. 11-23.

Hewitt, R. and Inghilleri, M. (1993), "Oracy in the classroom: policy, pedagogy, and group oral work”, Anthropology and Education Quarterly, Vol. 24 No. 4, pp. 308-317.

Holquist, M. (Ed.) (1981), The Dialogic Imagination: Four Essays by M.M. Bakhtin, trans. Emerson, C. and Holquist, M., University of Texas Press, Austin.

Honig, A.S. (2007), "Oral language development", Early Child Development and Care, Vol. 177 Nos 6/7, pp. 581-613. 
Jones, D. (2007), “Speaking, listening, planning and assessing: the teacher's role in developing metacognitive awareness", Early Child Development and Care, Vol. 177 Nos 6/7, pp. 569-579.

Jones, D. and Hodson, P. (2012), Unlocking Speaking and Listening, Routledge/Taylor and Francis Group, New York, NY, London.

Littleton, K., Mercer, N., Dawes, L., Wegerif, R., Rowe, D. and Sams, C. (2005), "Talking and thinking together at key stage 1", Early Years: An International Research Journal, Vol. 25 No. 2, pp. 167-182.

Lyle, S. (2008), "Dialogic teaching: discussing theoretical contexts and reviewing evidence from classroom practice", Language and Education, Vol. 22 No. 3, pp. 222-240.

Mercer, N., Dawes, L. and Kleine Staarman, J. (2009), "Dialogic teaching in the primary science classroom”, Language and Education, Vol. 23 No. 4, pp. 353-369.

Monash University Employer Survey (2007), Employer Survey 2007, Part 1: Australian Based Employers Summary Report, Centre for Higher Education Quality, Monash, VIC.

Neelands, J. (1992), Learning Through Imagined Experience, Hodder \& Stoughton Educational, London.

O’Neill, C. (1995), Dramaworlds: A Framework for Process Drama, Heinemann, Portsmouth, NH.

O’Toole, J. (1991), Oracy, the Forgotten Basic: A Provocation, Issues in Education, Ministerial Consultative Council on Curriculum, Brisbane.

O’Toole, J. and Stinson, M. (2013a), “Arts packages of practice: drama”, QUT Creative Industries \& Education Services Australia, available at: http://artspop.org.au/content/view/?docid= 28-VYNxjlWqqko

O’Toole, J. and Stinson, M. (2013b), "Drama, speaking and listening: the treasure of oracy", in Anderson, M. and Dunn, J. (Eds), How Drama Activates Learning: Contemporary Research and Practice, Bloomsbury, London.

Pikulski, J.J. and Chard, D.J. (2005), "Fluency: bridge between decoding and reading comprehension", The Reading Teacher, Vol. 58 No. 6, pp. 510-519.

Podlozny, A. (2000), "Strengthening verbal skills through the use of classroom drama: a clear link", The Journal of Aesthetic Education, Vol. 34 Nos 3/4, pp. 239-275.

Townsend, T., Dempster, N., Johnson, G., Bayetto, A. and Stevens, E. (2015), "Leadership with a purpose: a report on five case studies of Principals As Literacy Leaders (PALL) schools (Tasmania)", Research report, Griffith Institute for Educational Research, Brisbane.

University of South Australia Employer Survey (2008), UniSA Employer Feedback Survey External Report, University of South Australia, Adelaide, SA.

Vygotsky, L. (1978), Mind in Society: The Development of Higher Psychological Processes, Harvard University Press, Cambridge, MA.

Wagner, B.J. (1998), Educational Drama and Language Arts: What Research Shows, Heinemann, Portsmouth, $\mathrm{NH}$.

\section{Corresponding author}

Madonna Stinson can be contacted: m.stinson@griffith.edu.au

For instructions on how to order reprints of this article, please visit our website:

www.emeraldgrouppublishing.com/licensing/reprints.htm

Or contact us for further details: permissions@emeraldinsight.com 


\section{AUTHOR QUERIES}

\section{AUTHOR PLEASE ANSWER ALL QUERIES}

AQau-Please confirm the given-names and surnames are identified properly by the colours. = Given-Name, $\boldsymbol{a}=$ Surname The colours are for proofing purposes only. The colours will not appear online or in print. AQ1- Please provide publisher location for the following reference: Alexander, 2005. 